DOI: 10.20472/IAC.2018.043.010

\author{
ABEID FRANCIS GASPAR \\ Institute of Finance Management, Tanzania, United Republic of
}

\title{
STAKEHOLDERS' PERSPECTIVES ON ACCOUNTABILITY IN TANZANIAN LOCAL GOVERNMENTS
}

\begin{abstract}
:
This paper explores accountability in local government authorities (LGAs) in Tanzania from the perspectives of different stakeholders. The purpose was to examine the participants' understandings and practice of accountability in the context of the LGAs.

The study used an interpretive methodology and data were gathered through in-depth interviews, documentary review, and observation particularly in meetings. The research involved five groups of participants, namely, the local and central government executives, councilors, external auditors, and members of the parliamentary committee responsible for the accounts of LGAs.

The respondents described accountability in terms of relationships between parties, whereby one party has both specified and unspecified responsibilities and a duty to demonstrate discharge of the same to the other interested parties. Accountability was mainly associated with the power of the accountee to hold the accountor to account. Six typologies of accountability relationships were observed. These include subordinate-superior/managerial, executive-councilor, political, public, professional, and administrative. The study also found a tendency to pay more attention to the perceived 'sensitive accountees' and a poor sense of public accountability and accountability to councilors amongst the local government executives. The local government participants who were considered to play less important roles and/or were less powerful were perceived to have limited need for both accounting and other information related to the discharge of accountability.
\end{abstract}

\section{Keywords:}

Accountability, Tanzanian, Local Government

JEL Classification: H83 